\title{
THE
}

\section{Nicotinamide complex of silver(III) with expanded coordination number}

Yunfu Sun

University of Rhode Island

Louis J. Kirschenbaum

University of Rhode Island, Ikirsch@chm.uri.edu

Follow this and additional works at: https://digitalcommons.uri.edu/chm_facpubs

The University of Rhode Island Faculty have made this article openly available.

Please let us know how Open Access to this research benefits you.

This is a pre-publication author manuscript of the final, published article.

Terms of Use

This article is made available under the terms and conditions applicable towards Open Access

Policy Articles, as set forth in our Terms of Use.

\section{Citation/Publisher Attribution}

Yunfu Sun \& Louis J. Kirschenbaum (2018) Nicotinamide complex of silver(III) with expanded coordination number, Journal of Coordination Chemistry, DOI: 10.1080/00958972.2018.1497790.

Available at: https://doi.org/10.1080/00958972.2018.1497790 


\section{Journal of Coordination Chemistry}

\section{Nicotinamide complex of silver(III) with expanded coordination number}

\section{Yunfu Sun \& Louis J. Kirschenbaum}

To cite this article: Yunfu Sun \& Louis J. Kirschenbaum (2018): Nicotinamide complex of silver(III) with expanded coordination number, Journal of Coordination Chemistry, DOI: 10.1080/00958972.2018.1497790

To link to this article: https://doi.org/10.1080/00958972.2018.1497790

Accepted author version posted online: 10 Jul 2018.

Submit your article to this journal ๘

III Article views: 1

View Crossmark data $₫$ 


\title{
Nicotinamide complex of silver(III) with expanded coordination number
}

\author{
YUNFU SUN ${ }^{\dagger}$ and LOUIS J. KIRSCHENBAUM* \\ Department of Chemistry, University of Rhode Island, Kingston, RI 02881, USA
}

In strongly alkaline media $\left(\left[\mathrm{OH}^{-}\right] \geq 0.12 \mathrm{M}\right)$, nicotinamide (nica) forms a complex with squareplanar $\mathrm{Ag}(\mathrm{OH})_{4}{ }^{-}$[nica] $\geq 0.05 \mathrm{M}$. The complex decomposes in seconds to nicotinamide $\mathrm{N}$-oxide. The correlation of maximum absorbance of the complex with concentrations of nicotinamide and hydroxide requires that the complex is either the five-coordinate $\mathrm{Ag}(\mathrm{OH})_{4}\left(\mathbf{H}_{-1} \text { nica }\right)^{2-}$ or the sixcoordinate $\mathrm{Ag}(\mathrm{OH})_{5}(\text { nica })^{2-}$. Comparison with the reactions of $\mathrm{Ag}(\mathrm{OH})_{4}^{-}$with nicotinate ion (nic') and acetamide under similar conditions indicates that nicotinamide coordinates with $\mathrm{Ag}(\mathrm{OH})_{4}{ }^{-}$by the amido group rather than the nitrogen on the pyridine ring or the amido oxygen. Kinetics of the $\mathrm{Ag}(\mathrm{III})$ - nica redox reaction are consistent with direct reaction between nicotinamide and uncoordinated $\mathrm{Ag}\left(\mathrm{OH}_{4}\right)^{-}$. Oxidation takes place at the pyridine ring, yielding nicotinamide $\mathrm{N}$-oxide. Silver(III) is reduced to monovalent silver.

Keywords: Silver(III); Kinetics; Nicotinamide; Intermediate; Complex

\section{Introduction}

The tervalent oxidation state of silver forms only a limited number of complexes. The simplest form of $\mathrm{Ag}(\mathrm{III})$ is $\mathrm{Ag}(\mathrm{OH})_{4}[1,2]$, which is prepared by electrolysis in alkaline media. Of the complexes which have been formed directly from $\operatorname{Ag}(\mathrm{OH})_{4}$, only those with periodate and tellurate ligands are more stable than the parent ion $[2 a, b]$. Other spectrally identifiable complexes include those with nitrogen donors, including azide [3], tri- and tetraglycine [4a]. Dimethylglyoximate (dmg) and related ligands form pseudomacrocyclic adducts [4b]. Divalent and tervalent silver $\mathrm{N}_{4}$-macrocycles with significant stability have been prepared by $\operatorname{Ag}(\mathrm{I})$ oxidation [5] as have $\mathrm{Ag}(\mathrm{III})$ derivatives of diguanide [6, 7]. A silver(III) transient with a tridentate dicarboxamite ligand has been identified by electrospray mass spectrometry [8]. $\mathrm{Ag}(\mathrm{OH})_{4}{ }^{-}$is square-planar with a low spin $\mathrm{d}^{8}$ electron configuration. It is a strong oxidizing agent $[3-5,9,10]$,

\footnotetext{
†Present address: Mylan Pharmaceuticals Inc., Morgantown, WV 26505, USA

*Corresponding author. Email: LKirsch@chm.uri.edu
} 
and reactions tend to be initiated by axial attack followed by replacement of a bound hydroxyl and/or redox. In the present study, we have considered the redox reaction between $\operatorname{Ag}(\mathrm{OH})_{4}{ }^{-}$and nicotinamide, and find a spectrally distinct intermediate complex that can only be characterized as containing $\operatorname{Ag}(\mathrm{III})$ with an expanded coordination sphere. The well-characterized nicotinamide complexes include those with cobalt(III) [11], palladium(II) [12], nickel(II) [13] and other transition metals [14]. Nicotinamide (or niacinamide), scheme 1, has three potential donor atoms and in principle any of these atoms may coordinate. However, nicotinamide is normally monodentate, coordinating through the pyridine ring nitrogen $[12,13,15]$ or either the amido oxygen or nitrogen [14b]. Nicotinamide bridging complexes have also been reported [16].

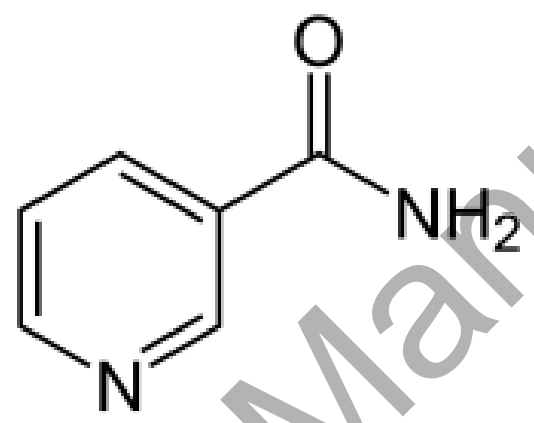

Scheme 1. Nicotinamide

\section{Experimental}

\subsection{Solutions}

Solutions of $\mathrm{Ag}(\mathrm{OH})_{4}{ }^{-}$and $\mathrm{NaClO}_{4}$ were prepared as described previously [2b, 17]. In order to prevent the hydrolysis of nicotinamide (to nicotinic acid and ammonia) [18], nica solutions were prepared in $1.2 \mathrm{M} \mathrm{NaClO}_{4}$ from the solid (Sigma >98\%) immediately before use. The kinetic studies above $\left[\mathrm{OH}^{\top}\right]=0.6 \mathrm{M}$ were done by using stock $\mathrm{Ag}(\mathrm{OH})_{4}{ }^{-}$in $2.4 \mathrm{M} \mathrm{NaOH}$ instead of $1.2 \mathrm{M}$. Acetamide (Fisher $\sim 99 \%$ ) solutions were made in $1.2 \mathrm{M} \mathrm{NaClO}_{4}$ and nicotinate solution was made from nicotinic acid (Sigma >98\%) in $\mathrm{NaOH}$. Except as noted, all experiments were done at $1.2 \mathrm{M}$ ionic strength.

\subsection{Kinetics}

Kinetic experiments were performed by mixing equal volumes of the ligand and $\operatorname{Ag}(\mathrm{OH})_{4}{ }^{-}$ solutions in an Aminco-Morrow stopped-flow apparatus interfaced to a PC at the appropriate 
temperature (generally $25 \pm 0.1{ }^{\circ} \mathrm{C}$ ), alkalinity, and ionic strength. The reaction traces show an increase and then decrease of absorbance due to the formation and decomposition of a yellow intermediate complex. The reaction was followed at $390 \mathrm{~nm}$, where the absorbance of the complex is close to maximum and that of $\mathrm{Ag}(\mathrm{OH})_{4}{ }^{-}$is small. A representative reaction trace is shown in figure 1. Because of the high absorbance of nicotinamide below $300 \mathrm{~nm}, \mathrm{Ag}(\mathrm{OH})_{4}{ }^{-}$could not be monitored around its maximum absorbance $(267 \mathrm{~nm})$.

Kinetic data were fitted by a two-exponential equation ("rise-fall") using the Kinfit routine (OLIS). The pre-exponential for the first phase was taken to be the absorbance of an equilibrium mixture of $\mathrm{Ag}(\mathrm{OH})_{4}{ }^{-}$and the nicotinamide complex. The ratios of the observed first-order rate constants for the formation $\left(k_{f}\right)$ and decomposition $\left(k_{d}\right)$ steps were generally within a factor of five.

\subsection{Spectra}

Rapid UV-visible spectra were recorded on a Beckman DU 7500 diode array spectrophotometer at $\sim 5^{\circ} \mathrm{C}$. Figure 2 illustrates the spectral changes over the course of the reaction. EPR spectra of rapidly frozen reaction mixtures were taken on a Bruker ER 220D-LR ESR spectrometer with an ER 4111 VT variable-temperature system at $123 \mathrm{~K}$.

\subsection{Product analysis}

The oxidation product was analyzed by thin layer chromatography (TLC). "Concentrated" silver(III) solutions, $\left(\left[\mathrm{Ag}(\mathrm{OH})_{4}\right]^{-} \approx 2 \times 10^{-3} \mathrm{M}\right)$, were made and mixed with a small volume of very concentrated nicotinamide solution ([nica] $>2 \mathrm{M}$ ) so as to minimize the effect of dilution while maintaining a large excess of nica. The mixture was then neutralized with $\mathrm{HCl}$ to about $\mathrm{pH} 6$ and the $\mathrm{AgCl}$ precipitate centrifuged off. A drop of the neutralized centrifugate was spotted on a Polygram TLC plate pre-coated with a $0.2 \mathrm{~mm}$ layer of silica gel N-HR/UV 254 (MachereyNagel+C., Germany). Ascending TLC was performed in a glass developing chamber saturated with absolute ethanol [19]. The solvent front was run to a height of $15 \mathrm{~cm}$, and the spots were detected by a multiband UV lamp (UVSL-58) at the long wavelength (366 nm). 


\section{Results}

\subsection{Complex formation}

When basic solutions of $\mathrm{Ag}(\mathrm{OH})_{4}{ }^{-}$and nicotinamide are mixed, there is a rapid appearance of a golden-yellow color due to the formation of a $\mathrm{Ag}(\mathrm{III})$ complex. The color disappears within a few seconds at room temperature (figure 1).

Dividing the equilibrium limiting absorbances, $\mathrm{A}_{\mathrm{T}}$, obtained from the kinetic analysis by initial $\mathrm{Ag}(\mathrm{III})$ concentration gives the apparent extinction coefficient $\left(\varepsilon_{\text {app }}\right)$. Figure 3 plots values of $\varepsilon_{\text {app }} v s$ nicotinamide concentrations at different $\left[\mathrm{OH}^{-}\right]$and shows an increase of absorbance with both hydroxide and nicotinamide concentrations. The increase in $\varepsilon_{\text {app }}$ with both [nica] and [ $\left.\mathrm{OH}^{-}\right]$ suggests an equilibrium of the type:

$$
\mathrm{Ag}(\mathrm{OH})_{4}^{-}+\mathrm{OH}^{-}+\text {nica } \stackrel{\mathrm{K}_{\mathrm{cx}}}{\longrightarrow} \mathrm{Cx}
$$

If we assume only one complex, the sum of the concentrations of the two silver-containing species equals the total concentration, $[\mathrm{Ag}(\mathrm{III})]_{\mathrm{T}}$. Thus, the limiting absorbance $\left(\mathrm{A}_{\mathrm{T}}\right)$ at a given $\left[\mathrm{OH}^{-}\right]$and [nica] can be defined as in equation 2:

$$
\begin{aligned}
\mathrm{A}_{\mathrm{T}} & =\varepsilon_{\mathrm{app}}[\mathrm{Ag}(\mathrm{III})]_{\mathrm{T}} \\
& =\varepsilon_{\mathrm{app}}\left(\left[\mathrm{Ag}(\mathrm{OH})_{4}{ }^{-}\right]+[\mathrm{CX}]\right) \\
& \left.=\varepsilon_{\mathrm{Ag}(\mathrm{OH}) 4^{-}}\left[\mathrm{Ag}(\mathrm{OH})_{4}\right]^{-}\right]+\varepsilon_{\mathrm{CX}}[\mathrm{CX}]
\end{aligned}
$$

Combining equation 2 with the equilibrium expression 3 , leads to equation 4 :

$$
\begin{aligned}
& \mathrm{K}_{\mathrm{cx}}=\frac{[\mathrm{Cx}]}{\left[\mathrm{Ag}(\mathrm{OH})_{4}^{-}\right]\left[\mathrm{OH}^{-}\right][\text {nica }]} \\
& \varepsilon_{\mathrm{app}}=\frac{\varepsilon_{\mathrm{Ag}(\mathrm{OH})_{4-}^{-}}+\varepsilon_{\mathrm{Cx}} \mathrm{K}_{\mathrm{cx}}\left[\mathrm{OH}^{-}\right][\text {nica }]}{1+\mathrm{K}_{\mathrm{cx}}\left[\mathrm{OH}^{-}\right][\text {nica }]}
\end{aligned}
$$


Using the experimental value of $\varepsilon_{\mathrm{Ag}(\mathrm{OH}) 4-}=368 \mathrm{M}^{-1} \mathrm{~cm}^{-1}$ and applying a non-linear least squares analysis (weighted by $1 / \varepsilon_{\text {app }}$ ) to equation 4 gave a good fit with the resulting values $\mathrm{K}_{\mathrm{cx}}=2.1 \pm$ $0.2 \mathrm{M}^{-2}$ and $\varepsilon_{\mathrm{Cx}}=(4.8 \pm 0.2) \times 10^{3} \mathrm{M}^{-1} \mathrm{~cm}^{-1}$ (at $390 \mathrm{~nm}$ ). A point-by-point spectral comparison of the complex and $\mathrm{Ag}(\mathrm{OH})_{4}{ }^{-}$is shown in figure 4.

The confirmation of complex formation according to equation 1 is in opposition to previous results where $\operatorname{Ag}(\mathrm{III})$ complex formation involves displacement of hydroxide. In other systems [3-5], the lower hydroxide concentrations favor complex formation and, thus, increase the absorbance in the visible region. The possibility that higher order nicotinamine complexes are formed which absorb less than the mono-complex at $390 \mathrm{~nm}$ might explain the hydroxide dependence alone, but not in combination with the nicotinamide results. If the absorbance decrease were due to the formation of these complexes, then the absorbance would decrease with [nica] as well because higher nicotinamide concentrations also favor higher complexes. Thus, we conclude that the complex is either the six-coordinate $\mathrm{Ag}(\mathrm{OH})_{5}(\text { nica })^{2-}$ or the deprotonated five-coordinate $\mathrm{Ag}(\mathrm{OH})_{4}\left(\mathbf{H}_{-1} \mathbf{N i c a}\right)^{2-}$.

\subsection{Formation kinetics}

The formation of the complex in the initial phase of the reaction is first-order in $[\mathrm{Ag}(\mathrm{III})]_{\mathrm{T}}$. Values of the observed pseudo-first-order rate constant, $\mathrm{k}_{\mathrm{c}}$, are given in table $\mathrm{S} 1$. The data show a dependence on both nicotinamide and hydroxide concentrations as shown in figure 5. Data analysis leads to the following empirical rate law (equation 5):

$$
\mathrm{k}_{\mathrm{c}}=\frac{\mathrm{A}[\text { nica }]+\mathrm{B}\left[\mathrm{OH}^{-}\right]}{\left[\mathrm{OH}^{-}\right]+\mathrm{C}[\text { nica }]+\mathrm{D}[\text { nica }]\left[\mathrm{OH}^{-}\right]}
$$

Weighed non-linear squares analysis yields $\mathrm{A}=2.3 \pm 0.2 \mathrm{~s}^{-1}, \mathrm{~B}=0.16 \pm 0.02 \mathrm{~s}^{-1}, \mathrm{C}=$ $0.12 \pm 0.03$ and $\mathrm{D}=1.0 \pm 0.1 \mathrm{M}^{-1}$. The rate law suggests parallel reaction paths.

\subsection{Decomposition products and stoichiometry}

The golden-yellow Ag(III)-nicotinamide complex decomposes in a few seconds, resulting in a clear colorless solution. $\mathrm{AgCl}$ precipitation experiments show that the reduction of silver is a two- 
electron process yielding $\operatorname{Ag}(\mathrm{I})$. $\mathrm{Ag}(\mathrm{I})$ forms highly stable complexes with nicotinamide [20], and no precipitation was observed even at the lowest nicotinamide concentration $(0.05 \mathrm{M})$.

The TLC separation gave two species with $\mathrm{R}_{\mathrm{F}}=0.54$ and $\mathrm{R}_{\mathrm{F}}=0.15$ when run in absolute ethanol for about $6 \mathrm{~h}$. The two spots correspond to nicotinamide and nicotinamide $\mathrm{N}$-oxide (nico), respectively. Literature $R_{F}$ values are 0.60 and 0.17 , respectively [16]. Nicotinic acid $\left(R_{F}=0.08\right)$ was not found. The presence of nicotinamide N-oxide was also confirmed by its UV absorbance maximum at $308 \mathrm{~nm}$ where it has an extinction coefficient $\varepsilon=10^{2.7}$ [21].

Since high concentrations of nicotinamide are necessary to get both complexation and rapid decomposition, stoichiometric measurements on the redox reaction are impractical. However, the product analysis accounts for the overall reaction (equation 6):

$$
\mathrm{Ag}(\mathrm{OH})_{4}{ }^{-}+\text {nica } \rightarrow \longrightarrow \mathrm{Ag}(\mathrm{I})+\text { nico }+2 \mathrm{OH}^{-}+\mathrm{H}_{2} \mathrm{O}
$$

\subsection{Decomposition kinetics}

The decomposition of the complex is first-order in $[\mathrm{Ag}(\mathrm{HII})]$ with pseudo-first-order rate constants, $\mathrm{k}_{\mathrm{d}}$, plotted in figure 6 (data are in table S1). The following simplest empirical relationship (equation 7):

$$
\mathrm{k}_{\mathrm{d}}=\frac{\mathrm{A}^{\prime}[\text { nica }]}{1+\mathrm{B}^{\prime}\left[\mathrm{OH}^{-}\right][\text {nica }]}
$$

gives a satisfactory fit with $\mathrm{A}^{\prime}=1.01 \pm 0.02 \mathrm{M}^{-1} \mathrm{~s}^{-1}$ and $\mathrm{B}^{\prime}=2.6 \pm 0.2 \mathrm{M}^{-2}$.

The lack of any [nica] ${ }^{2}$ terms in the decomposition rate law indicates that the electron transfer takes place either between $\mathrm{Ag}(\mathrm{OH})_{4}{ }^{-}$and nicotinamide or within complex/intermediate molecules. Hence, an intermolecular electron transfer between the complex and nicotinamide, which would require the attack of a second nicotinamide on the complex or intermediate, is unlikely. The proposed mechanism (reactions 8 and 9) leads to equation 10 which fits well with the redox results. Comparing:

$$
\mathrm{Ag}(\mathrm{OH})_{4}{ }^{-}+\mathrm{OH}^{-}+\text {nica } \underset{\mathrm{k}^{\prime}}{\stackrel{\mathrm{K}_{\mathrm{cx}}}{\longrightarrow}}
$$




$$
\begin{aligned}
& \mathrm{Ag}(\mathrm{OH})_{4}{ }^{-}+\text {nica } \underset{\mathrm{k}_{\mathrm{d}}{ }^{\prime}[\text { nica }]}{\longrightarrow} \text { products } \\
& \mathrm{k}_{\mathrm{d}}=\frac{1+\mathrm{K}_{\mathrm{cx}}[\text { nica }]\left[\mathrm{OH}^{-}\right]}{}
\end{aligned}
$$

equations 7 and 10, the equilibrium constant is determined to be $2.63 \mathrm{M}^{-2}$, which is in good agreement with the value of $\mathrm{K}_{\mathrm{cx}}$ obtained from the absorbance analysis (Section 3.1). The comparison also gives $\mathrm{k}_{\mathrm{d}}{ }^{\prime}=1.01 \mathrm{M}^{-1} \mathrm{~s}^{-1}$. Recalculated values for $\mathrm{k}_{\mathrm{d}}$ are listed in table S1. An alternative, but less satisfying, treatment of the decomposition with two additional parameters is given in the Supplementary Material (S2).

\subsection{Reactions of $\mathrm{Ag}(\mathrm{OH})_{4}$ with acetamide and nicotinate ion}

Nicotinate ion (nic) does not form any visible complex with $\mathrm{Ag}(\mathrm{OH})_{4}^{-}$even at [nic ${ }^{-}$] $=1.0 \mathrm{M}$. Nor were there any biphasic absorbance changes at $300<\lambda<500 \mathrm{~nm}$. Acetamide, on the other hand, shows intermediate formation followed by redox, but at a lower rate than nicotinamide. The three systems are compared in figure 7. It is also noticed that at the same ligand and $\operatorname{Ag}(\mathrm{OH})_{4}^{-}$ concentrations, the acetamide complex has a much smaller absorbance than that of nicotinamide at $390 \mathrm{~nm}$, either due to a smaller extinction coefficient or smaller equilibrium concentration or both. The slight decrease in absorbance of the nicotinate mixture is of similar magnitude to the spontaneous decomposition of $\mathrm{Ag}(\mathrm{OH})_{4}[2$ [b)].

\subsection{EPR Experiments and ionic strength dependence}

EPR experiments were carried out on quickly frozen reaction mixtures. The spectra were devoid of any signal, eliminating the possibility that the intermediate complex might contain monomeric divalent silver $[22,23]$. Detection of an EPR-active pseudo octahedral complex would also be unlikely in light of large ligand field splitting and/or zero field effects. Five coordinate complexes based on $\mathrm{C}_{2 \mathrm{v}}$ or $\mathrm{D}_{4 \mathrm{~h}}$ geometry would also be expected to be EPR silent.

The ionic strength dependence was investigated from $\mu=0.12 \mathrm{M}$ to $1.2 \mathrm{M}$ at $\left[\mathrm{OH}^{-}\right]=$ $0.12 \mathrm{M}$ and $25{ }^{\circ} \mathrm{C}$. The pseudo-first-order rate constants of complexation slightly increase with ionic strength, but plotting $\log \mathrm{k}_{\text {obsd }} v s \mu^{1 / 2} /\left(\mu^{1 / 2}+1\right)-0.05 \mu$ [24] was not linear, and the slopes of the curve are generally smaller than one. This can be explained by a mixture of reacting species (equation 5). The value of $\mathrm{k}_{\mathrm{d}}$ decreases with ionic strength, apparently due to the effect of ionic 
strength on the equilibrium constant. For equilibrium equation 1 , the ionic strength increase should increase its equilibrium constant [25]. Such an increase of equilibrium constant will decrease the amount of $\mathrm{Ag}(\mathrm{OH})_{4}{ }^{-}$present and thus decrease the decomposition rate.

\section{Discussion}

Although intermediates with expanded coordination spheres have been postulated in several $\mathrm{Ag}\left(\mathrm{OH}_{4}\right)^{-}$reactions $[17,26]$, this is the first example for which there is significant concentration and spectral evidence for a stoichiometry requiring five or six coordination. The maximum absorbance of the complex increases with both hydroxide and nicotinamide concentration, showing that the complex is formed by reaction of one hydroxide and one nicotinamide with $\left(\mathrm{Ag}(\mathrm{OH})_{4}{ }^{-}\right.$. While we are unable to definitively explain the rate data for intermediate formation, the complexity of equation 5 is not entirely unexpected. Both first-order and inverse hydroxide ion dependences have been observed in $\mathrm{Ag}(\mathrm{III})$ reactions, and an increase in rate with decreasing $\left[\mathrm{OH}^{-}\right]$has been attributed to either protolytic reaction of the ligand or formation of $\mathrm{Ag}\left(\mathrm{OH}_{3}\right) \mathrm{H}_{2} \mathrm{O}$ prior to the replacement of a bound hydroxide ion [3]. The equilibrium constant for protonation of $\mathrm{Ag}\left(\mathrm{OH}_{4}\right)^{-}$to give $\mathrm{Ag}(\mathrm{OH})_{3}\left(\mathrm{H}_{2} \mathrm{O}\right)$ is about $10^{-3}$ and $\mathrm{k}=0.6 \mathrm{~s}^{-1}$ for the transfer of a proton from water [27]. Thus, the trihydroxo species might provide a parallel kinetic path to axial complexation although significant replacement of $\left[\mathrm{OH}^{-}\right]$is inconsistent with the form of $\mathrm{K}_{\mathrm{cx}}$ (equation 3) as determined from the absorbance data. We have considered the following overall processes for complex formation: (a) a six-coordinate complex is formed with addition of neutral nicotinamide and $\mathrm{OH}^{-}$; (b) nicotinamide is deprotonated and then forms five-coordinate $\operatorname{Ag}(\mathrm{OH})_{4}\left(\mathbf{H}_{-1} \text { nica }\right)^{2-}$; (c) nicotinamide combines with $\mathrm{Ag}(\mathrm{OH})_{4}{ }^{-}$first and then is deprotonated to $\mathrm{Ag}(\mathrm{OH})_{4}\left(\mathbf{H}_{-1} \text { nica }\right)^{2-}$ or (d) nicotinamide reacts with two hydroxides to form a kind of intermediate (Int ${ }^{2-}$ ), that then complexes with $\mathrm{Ag}(\mathrm{OH})_{4}^{-}$as $\mathrm{Ag}(\mathrm{OH})_{3}(\mathbf{I n t})^{2-}$. In alternative (b), the deprotonation reaction of nicotinamide $\left(\mathrm{K}_{\mathrm{a}}=8 \times 10^{-2}\right.$ [28]) would promote a simple first-order dependence of complexation rate on hydroxide which contradicts the experimental results. In (d), nicotinamide has to react with two hydroxides before complexation since one hydroxide is needed to counter the hydroxide released from the $\mathrm{Ag}(\mathrm{OH})_{4}{ }^{-}$. Alternative (d) also leads to the positive dependence of complexation rate on hydroxide, and its need for an intermediate formed by nicotinamide's reacting with two hydroxides makes it even more unlikely. Thus, the proposed six- or five-coordination (a, c, or a combination) seems necessary to explain both the absorbance and kinetic data. We may also 
conclude that suppression of nica deprotonation is responsible for the inverse $\left[\mathrm{OH}^{-}\right]$contribution to $\mathrm{k}_{\mathrm{c}}$, thus reinforcing the participation of neutral nica.

The absence of an EPR signal precludes not only a monomeric $\operatorname{Ag}\left(\right.$ II) (d ${ }^{9}$ ) complex, but, even if five or six coordinate, the $\mathrm{Ag}(\mathrm{III})$-nica complex would be expected to be EPR silent. If there were a weak pseudo-octahedral ligand field around $\mathrm{Ag}(\mathrm{III})$, the anisotropy of the zero field splitting would provide a relaxation mechanism for the electron spin state [29]. Even high spin $\mathrm{Ni}(\mathrm{II}) \underline{\mathrm{O}}_{\mathrm{h}}$ complexes, which should have smaller zero-field splitting, show no EPR signal unless taken to extremely low temperature. A truly diamagnetic five- or six-coordinate $\mathrm{Ag}$ (III) complex is also possible since low-spin compounds predominate in higher oxidation states and for the second and third transition series. Thus we are unable to choose between the stoichiometrically ambiguous formulations of the complex given in Section 3.1.

Nicotinamide is known to hydrolyze to nicotinic acid and ammonia in both acidic and alkaline media [18, 30, 31]. Since strongly alkaline solutions were used in this study, the hydrolysis of nicotinamide has been of concern. By using neutral solutions of nicotinamide, the pre-mixing hydrolysis can be avoided. The reaction of nicotinamide and $\mathrm{Ag}(\mathrm{OH})_{4}{ }^{-}$is fast enough that it takes only tens of seconds to completion (decomposition of the complex). On this time scale, the hydrolysis is negligible. In fact, the product analysis, which usually took place within a few minutes after mixing, did not reveal any nicotinic acid or ammonia.

Because of the instability of the $\mathrm{Ag}(\mathrm{III})$ complex, it was not possible to determine the binding site spectroscopically. Product analysis shows that oxidation occurs at the pyridine ring, while comparison with nicotinate ion and acetamide indicates that the bonding occurs at the amido nitrogen rather than the pyridine nitrogen. The oxidation products are different from reactions of acetamide, formamide and other amides [32] which yield ammonia or amines and corresponding acids [31], but similar to the oxidations of pyridine [33] by polyacids [34], and of nicotinamide by hydrogen peroxide [35] and rat liver microsomes [36] which give the N-oxides. Unfortunately, the oxidation mechanisms in these cases are unknown. In light of the fact that the complex appears to involve binding at the amido group while redox occurs at the pyridine ring, we conclude that there are two modes of interaction between $\mathrm{Ag}(\mathrm{OH})_{4}{ }^{-}$and nicotinamide. When nicotinamide combines with $\mathrm{Ag}(\mathrm{OH})_{4}{ }^{-}$via its amido group, a complex is formed (equation 9); but the complex is a "dead end" in regard to the redox process. The redox reaction (equation 10) involves oxidation at the pyridine ring and does not require participation of $\mathrm{OH}^{-}$in a kinetically significant step. In the 
oxidation of several oxoanions by $\mathrm{Ag}(\mathrm{OH})_{4}{ }^{-}$, we postulated a mechanism in which a bound oxygen is transferred to an axially coordinated ligand followed by redox [37]. Analogous behavior does not seem possible in the present system, both because of the large distance between the amido group and the pyridine nitrogen, and the absence of favorable electronic properties as seen in the oxoanions.

Finally, we note that a somewhat more detailed alternative to equations 9 and 10 can be written (Supplementary Material), which divides the complex formation into two segments with the intermediate undergoing competitive oxidation-reduction. The additional parameter which results is relatively uncertain, has little effect on the analysis from the simpler treatment, thus, verifying that any common intermediate is of minor stoichiometric significance and does not allow an alternative intramolecular path to redox.

\section{Acknowledgements}

We thank Morgan Turano for conducting confirmatory experiments. This research was partially supported by a grant from the Petroleum Research Fund, administered by the American Chemical Society. This paper is dedicated to Dan Meyerstein, a giant of (among other things) inorganic chemistry with an amazing work ethic.

\section{Conflict of interest}

The authors have declared no conflict of interest.

\section{References}

[1] (a) H.N. Po. Coord. Chem. Rev., 20, 171 (1976). (b) W. Levason, N.D. Spicer. Coord. Chem. Rev., 76, 45 (1987).

[2] (a) G.L.Cohen, G. Atkinson. J. Electrochem. Soc., 115, 1236 (1968). (b) L.J.

Kirschenbaum, J.H. Ambrus, G. Atkinson. Inorg. Chem., 12, 2832 (1973). (c) I.R. ZamoraGarcia, A. Alatorre-Ordaz, J.G. Ibanez, M.G. Garcia-Jimenez, Y. Nosaka, T. Kobayashi, S. Sugita. Electrochim. Acta, 111, 268 (2013).

[3] E.T. Borish, L.J. Kirschenbaum. Inorg. Chem., 23, 2355 (1984).

[4] (a) L.J. Kirschenbaum, J.D. Rush. J. Am. Chem. Soc., 106, 1083 (1984). (b) L.J. Kirschenbaum, R.K. Panda, E.T. Borish, E. Mentasti. Inorg. Chem., 28, 3623 (1989). 
[5] (a) I.H. Clark, J.M. Harrowfield. Inorg. Chem., 23, 3740 (1984). (b) M. Pesavento, A. Profumo, T. Soldi, L. Fabbrizzi. Inorg. Chem., 24, 3873 (1985).

[6] (a) G.C. Allen, K.D. Warren. Inorg. Chem., 8, 1895 (1969). (b) S. Pal, E.J. Yoon, Y.K. Tak, E.C. Choi, J.M. Song. J. Am. Chem. Soc., 131, 16147 (2009). (b) A. Das, S. Mukhopadhyay. Polyhedron, 23, 895 (2004).

[7] L. Coghi, G. Pelizzi. Acta Crystallogr. Sect. B, 31, 131 (1975).

[8] P. Kumar, J. Roithová. Eur. J. Mass Spectrom., 18, 457 (2012).

[9] I.R. Zamora-Garcia, A. Alatorre-Ordaz, J.G. Ibanez, J.C. Torres-Elguera, K. Wrobel, S. Gutierrez-Granados. Chemophere, 191, 400 (2018).

[10] (a) L.J. Kirschenbaum, E.T. Borish, J.D. Rush. Isr. J. Chem., 25, 159 (1985).

(b) E.T. Borish, L.J. Kirschenbaum, E. Mentasti. J. Chem. Soc., Dalton Trans., 1789 (1985).

[11] D.G. Batyr, M.P. Starysh, V.N. Shafranskii, Yu.Ya. Kharitonoy. Russ. J. Inorg. Chem., 19, 1517 (1974).

[12] (a) A.Yu. Tsivadze, G.V. Tsintsadze, L.G. Chikhladze.Russ. J. Inorg. Chem., 30, 240 (1985). (b) L.S. Tikhonova, A.I. Stetsenko, L.I. Iozep, M.R. Grinbergs. Russ. J. Inorg. Chem., 30, 1623 (1985).

[13] G.V. Budu, L.V. Nazarova, A.P. Tkhoryak. Russ. J. Inorg. Chem., 22, 618 (1977).

[14] (a) I.S. Maslennikova. Russ. J. Phys. Chem., 55, 581 (1981). (b) C.N. Rao, B.K. Mohapatra, S. Guru. J. Indian Chem. Soc., 53, 1240 (1976). (c) A.Yu. Tsivadze, G.V. Tsintsadze, Yu.Ya. Kharitonov, L.V. Gverdtsiteli. Russ. J. Inorg. Chem., 23, 248 (1978). (d) L.V. Konovalov, I.S. Maslennikova, V.N. Shemyaskin. Russ. J. Inorg. Chem., 15, 1026 (1970).

[15] R.P. Eckberg, W.E. Hatfield. J. Chem. Soc., Dalton Trans., 1364 (1975).

[16] (a) R.G. Gaunder, H. Taube. Inorg. Chem., 9, 2627 (1970). (b) R.W. Craft, R.G. Gaunder. Inorg. Chem., 14, 1283 (1975).

[17] I. Kouadio, L.J. Kirschenbaum, R.N. Mehrotra, Y. Sun. J. Chem. Soc., Perkin Trans. II, 2123 (1990).

[18] P. Finholt, T. Higuchi. J. Pharm. Sci., 51, 655 (1962).

[19] L.A. Damani, L.H. Patterson, J.W. Gorrod. J. Chromatogr., 155, 337 (1978).

[20] R.K. Murmann, F. Basolo. J. Am. Chem. Soc., 77, 3484 (1955). 
[21] L.R. Caswell, F.C. Lee, L.T. Creagh. J. Heterocycl. Chem., 9, 551 (1972).

[22] J.D. Rush, L.J. Kirschenbaum. Polyhedron, 4, 1573 (1985).

[23] A. Ali, A.I. Shames, S. Gangopadhyay, D. Meyerstein. Transition Met. Chem., 29, 463 (2004).

[24] C.W. Davies, Ion Association, Butterworths: London, p 39 (1962).

[25] H.A. Laitinen, Chemical Analysis, McGraw-Hill Book Company, Inc.: New York, p 19 (1960).

[26] (a) J.D. Rush, L.J. Kirschenbaum. Inorg. Chem., 24, 744 (1985). (b) L.J. Kirschenbaum. J. Inorg. Nucl. Chem., 881 (1976).

[27] L.J. Kirschenbaum, L. Mrozowski. Inorg. Chem., 17, 3718 (1978).

[28] C. Tissier, M. Tissier. Bull. Soc. Chim. Fr., 3752 (1970).

[29] R.S. Drago, Physical Methods in Chemistry, W. B. Saunders Company: Philadelphia, Chapter 13 (1977).

[30] C.E. Efstathiou, D.P. Nikolelis, T.P. Hadjiioannou. Anal. Lett., 15A, 1179 (1982).

[31] H.H.G. Jellinek, M.G. Wayne. J. Phys. Colloid Chem., 55, 173 (1951).

[32] R.B. Homer, C.D. Johnson, The Chemistry of Amides, J. Zabicky (Ed.), Interscience Publishers: London, p 187 (1970).

[33] F. Ahmad, V. Baswani. Aust. J. Chem., 32, 537 (1979).

[34] (a) E.C. Taylor Jr., A.J. Crovetti. J. Org. Chem., 19, 1633 (1954). (b) E.C. Taylor Jr., A.J. Crovetti. Org. Synth., 37, 63 (1957).

[35] K. Nomura, M. Shin, K. Sano, T. Umezawa. Biochem. Pharm., 32, 934 (1983).

[36] R.A. Barnes, Pyridine and Its Derivatives, E. Klingsberg (Ed.), Part 1, Interscience Publishers: New York, p 1 (1962).

[37] (a) L.J. Kirschenbaum, I. Kouadio, E. Mentasti. Polyhedron, 8, 1299 (1989). (b) R.N. Mehrotra, L.J. Kirschenbaum. Inorg. Chem., 28, 4327 (1989). 


\section{Figure captions}

Figure 1. Formation and decomposition of the yellow complex at $390 \mathrm{~nm}$.

Figure 2. Rapid UV-visible scans of silver(III)-nica reaction mixtures at $\sim 5^{\circ} \mathrm{C}$. (a) 0 ; (b) 2 ; (c) 12 ; (d) 22; (e) 32 and (f) 52 seconds after mixing.

Figure 3. Apparent extinction coefficients from maximum absorbances at $25^{\circ} \mathrm{C}$. Solid lines are calculated from Equation 4.

Figure 4. Comparison spectra of the complex from kinetic parameters (+) vs $\mathrm{Ag}(\mathrm{OH})_{4}^{-}$(solid line).

Figure 5. Variation of $\mathrm{k}_{\mathrm{c}}$ with $\left[\mathrm{OH}^{-}\right]$and [nica] at $25^{\circ} \mathrm{C}$ and $\mu=1.2 \mathrm{M}$ (data in S1). Solid lines are calculated from the observed rate law (equation 5).

Figure 6. The $\left[\mathrm{OH}^{-}\right]$and [nica] dependence of the decomposition (redox) reaction at $25^{\circ} \mathrm{C}$ and $\mu=$ 1.2 M. Solid lines are calculated from the observed rate law (equation 7).

Figure 7. Kinetic reaction traces of $\mathrm{Ag}(\mathrm{OH})_{4}{ }^{-}$with nicotinate, acetamide and nicotinamide at $390 \mathrm{~nm}$. [L] $=0.5 \mathrm{M}, \mu=1.2 \mathrm{M}, 25^{\circ} \mathrm{C}$. (a) Nicotinate ion, (b) acetamide, (c) nicotinamide.

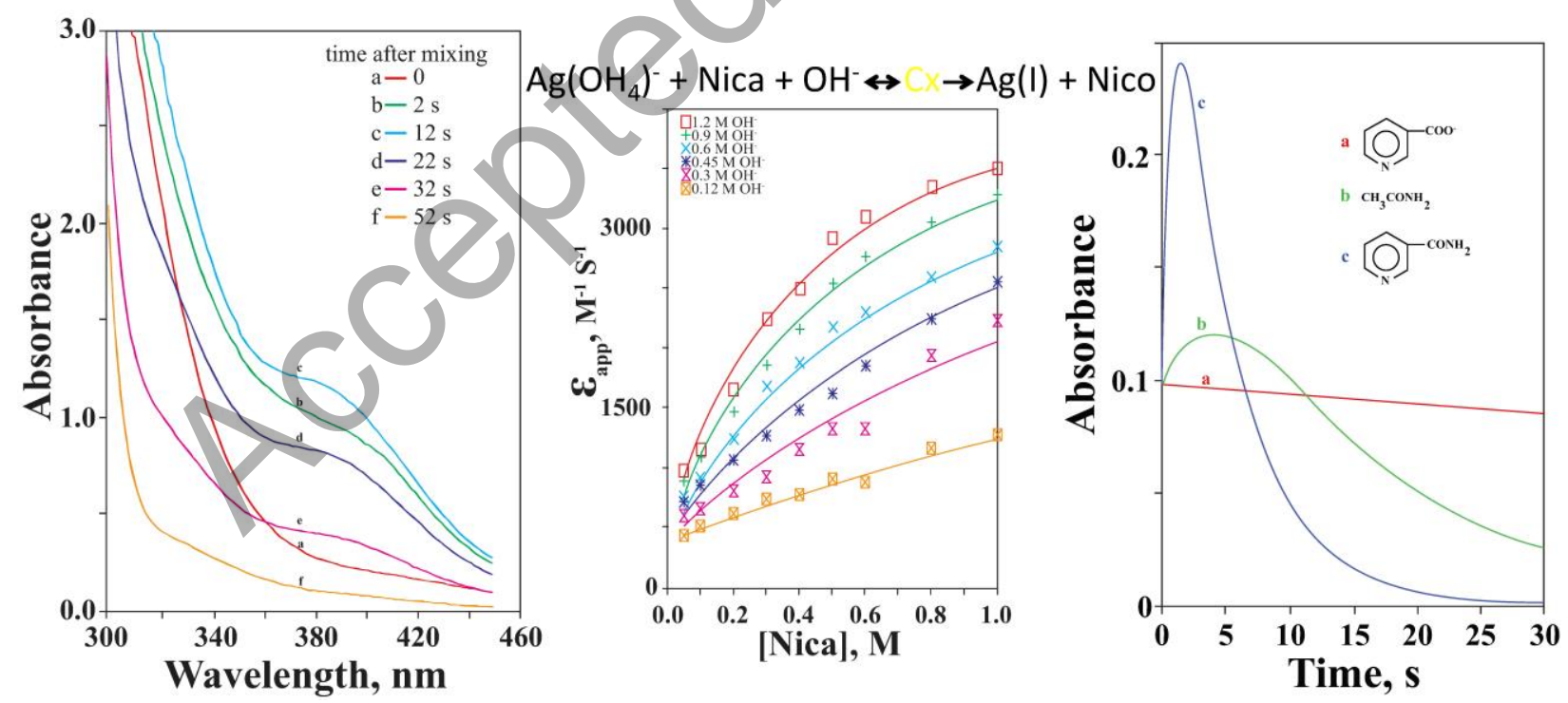




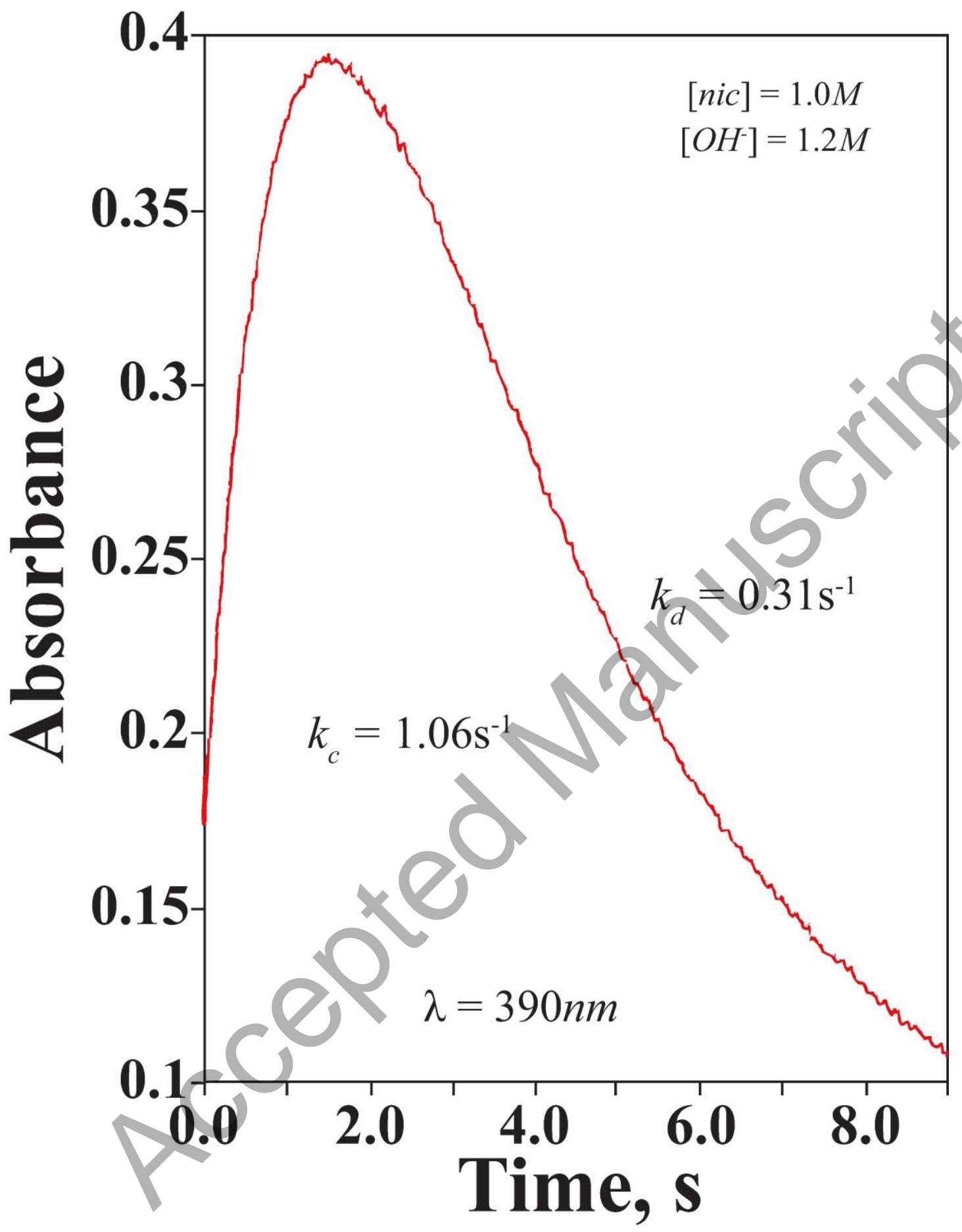




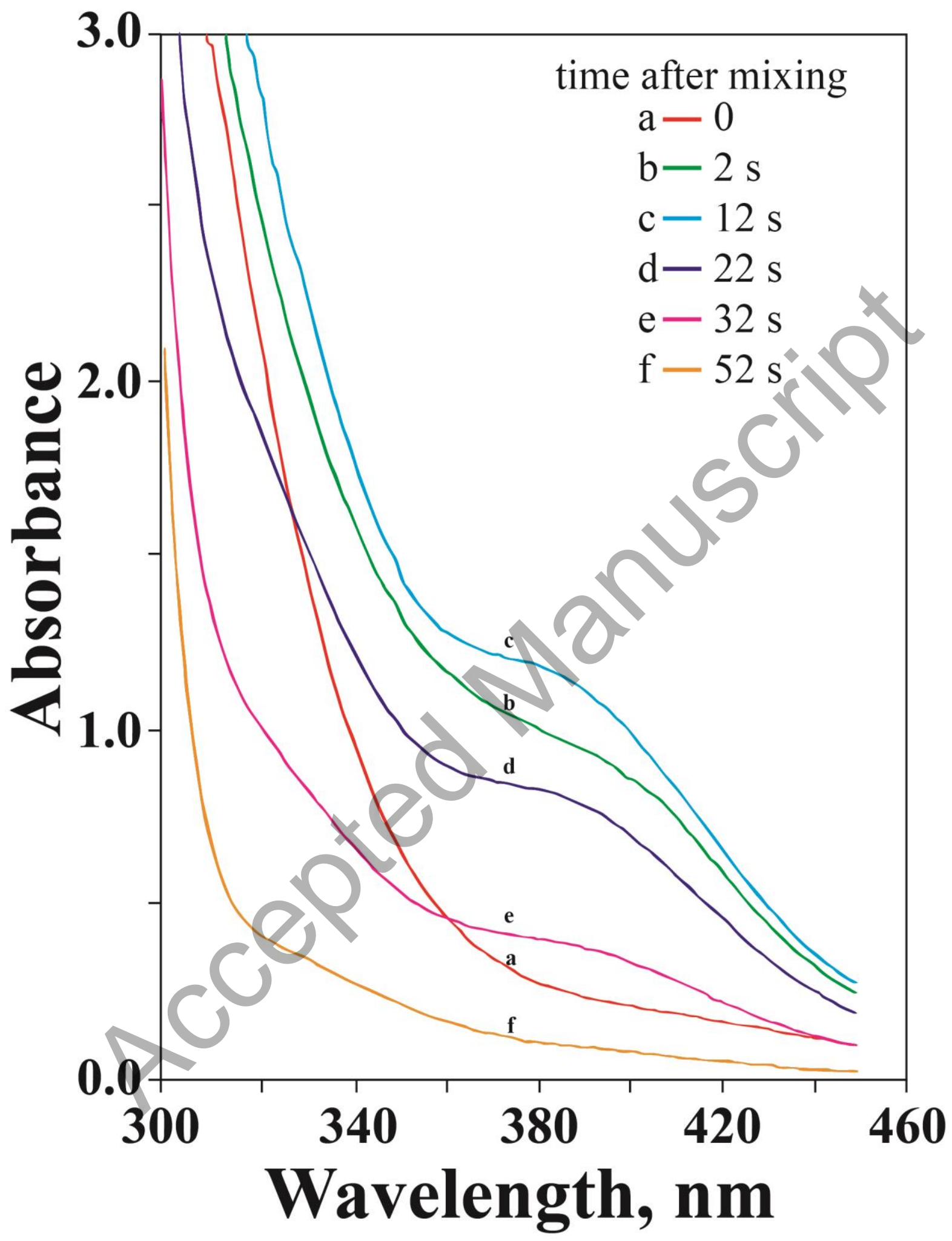




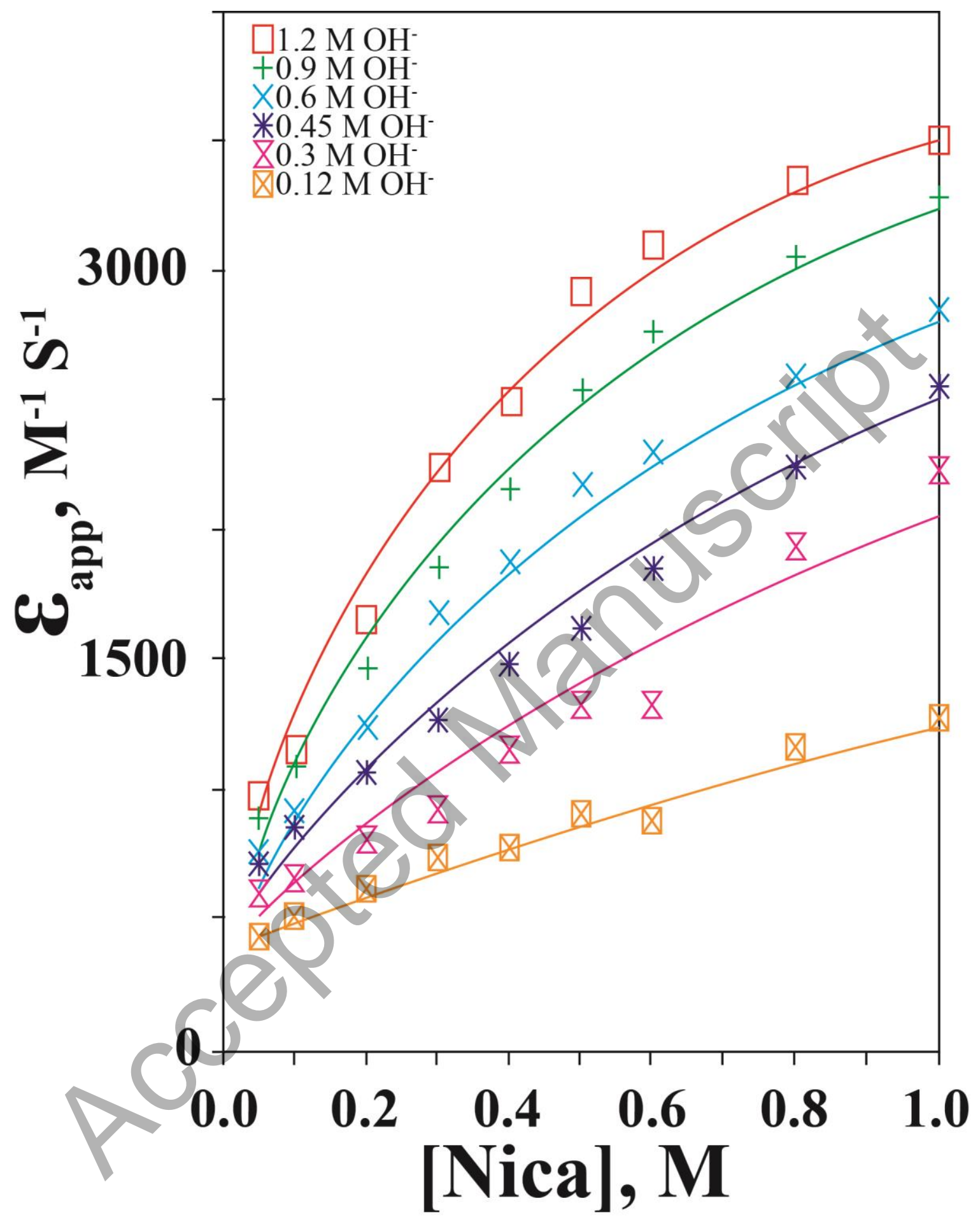




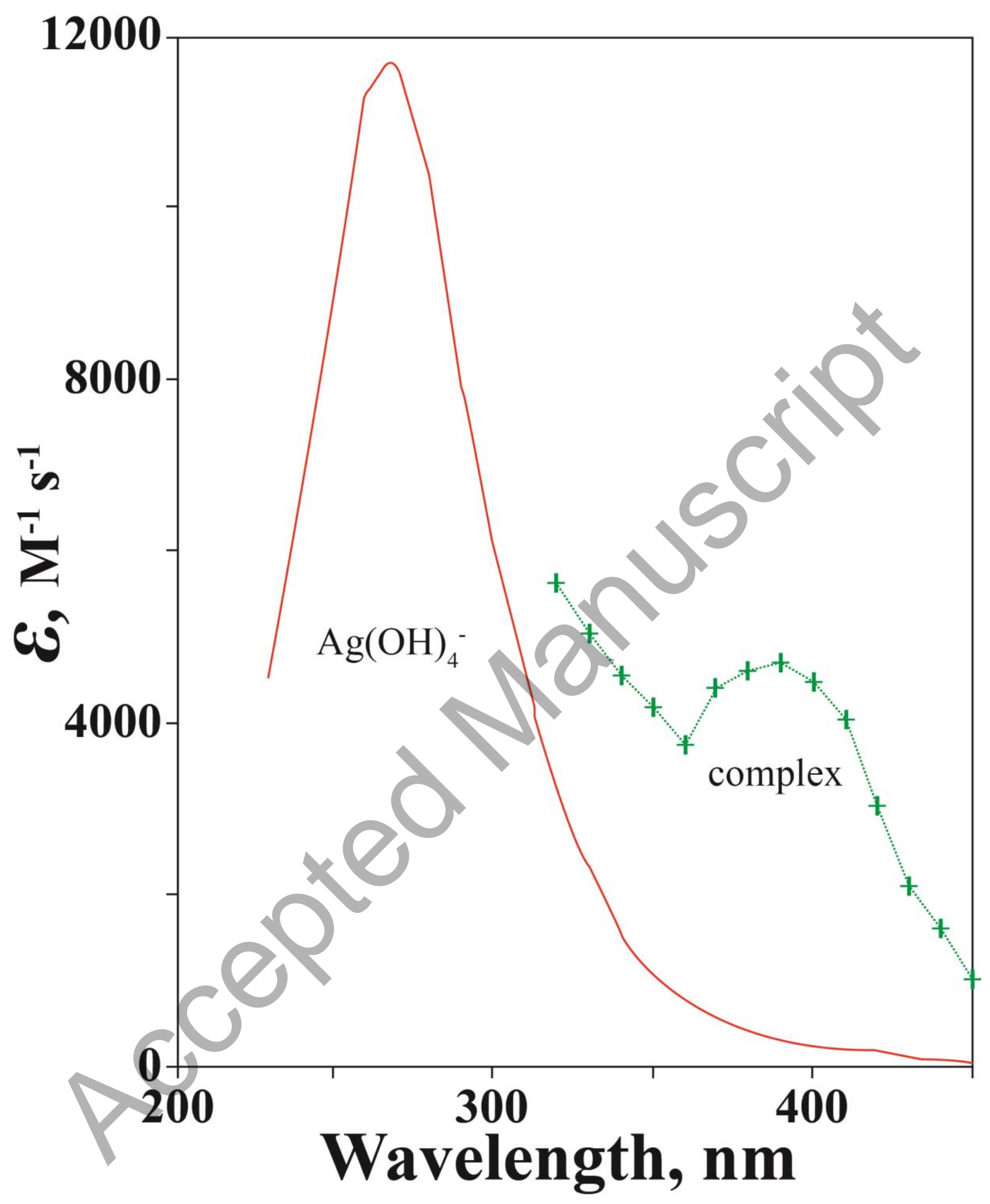




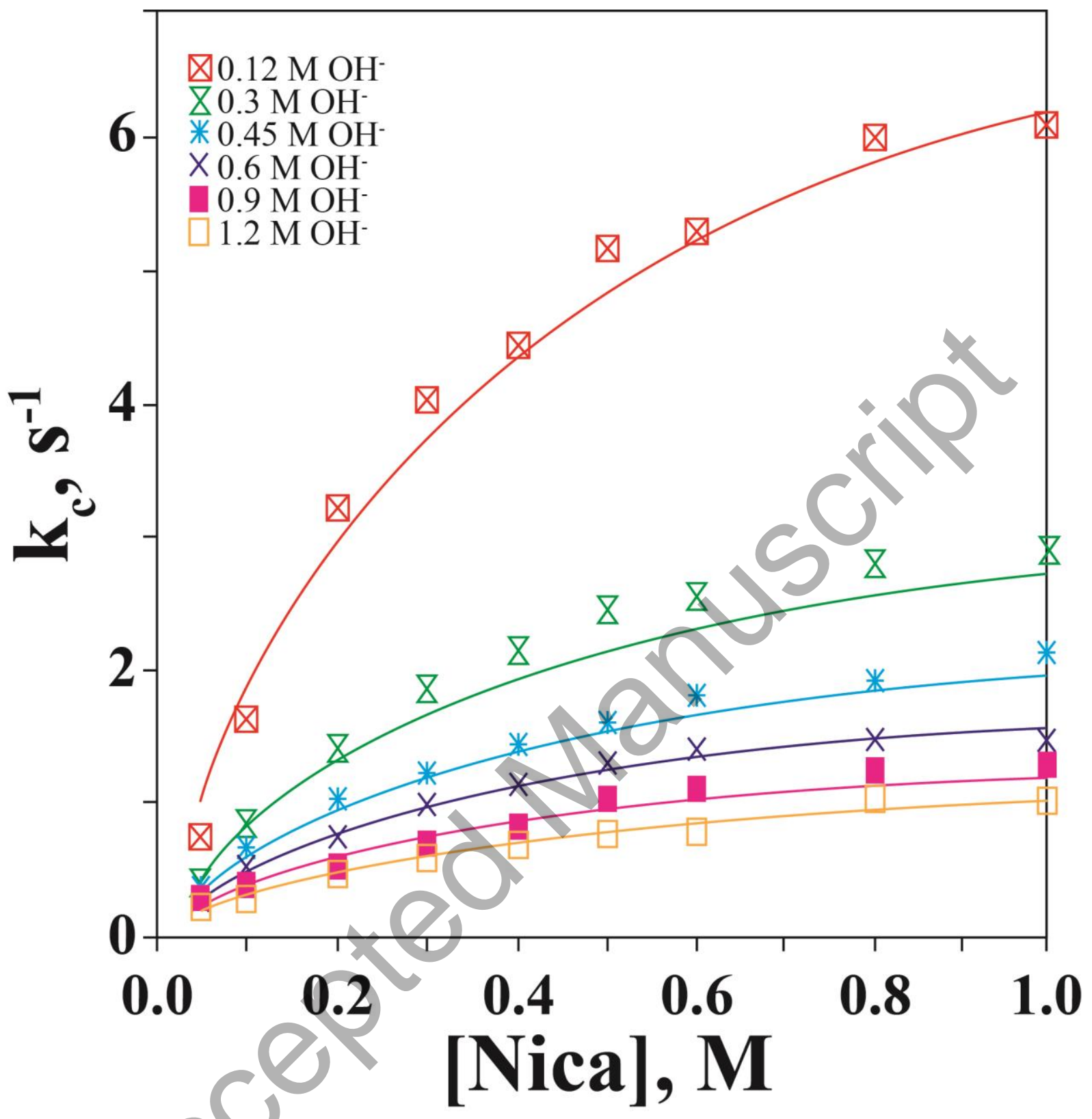




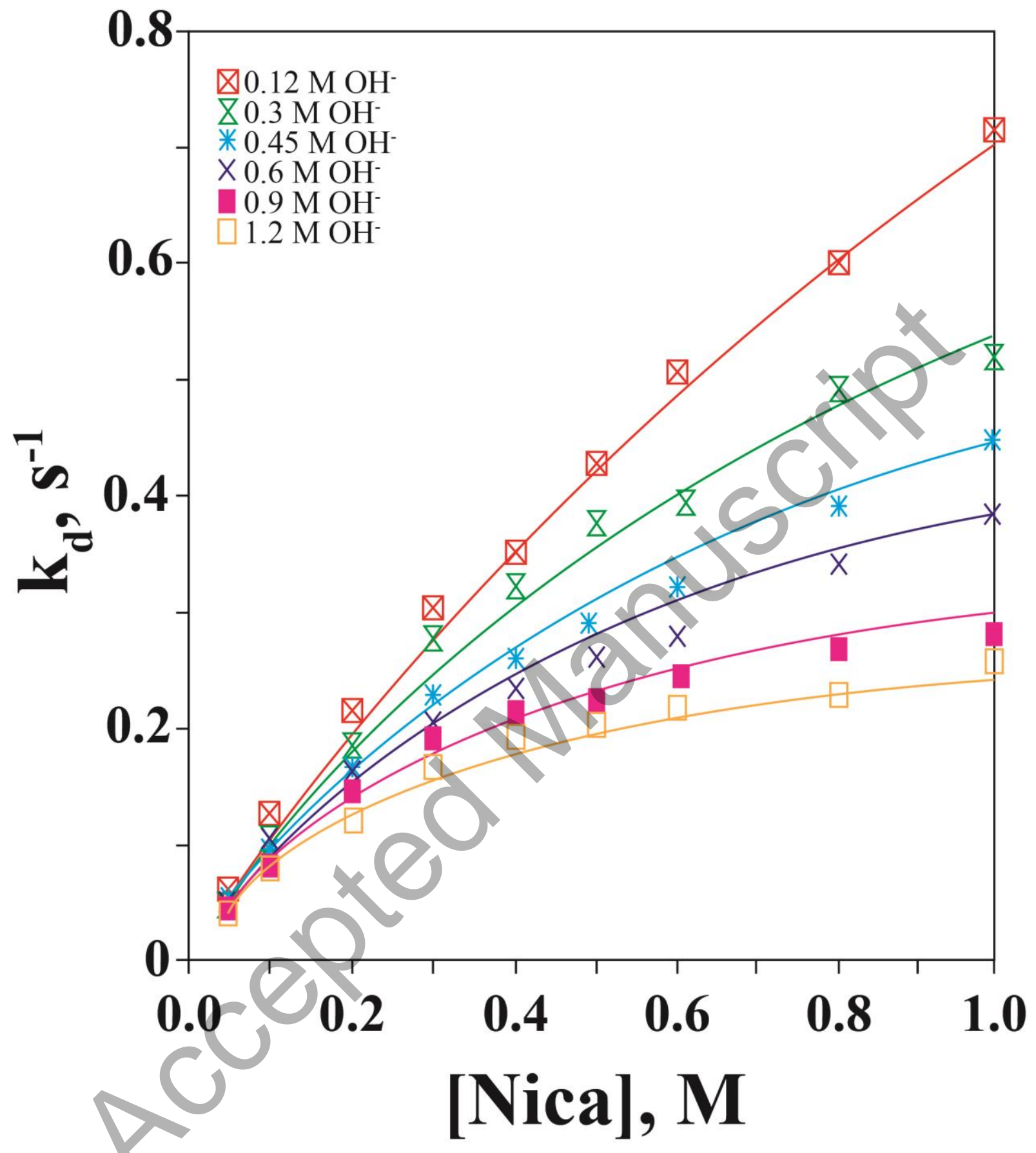




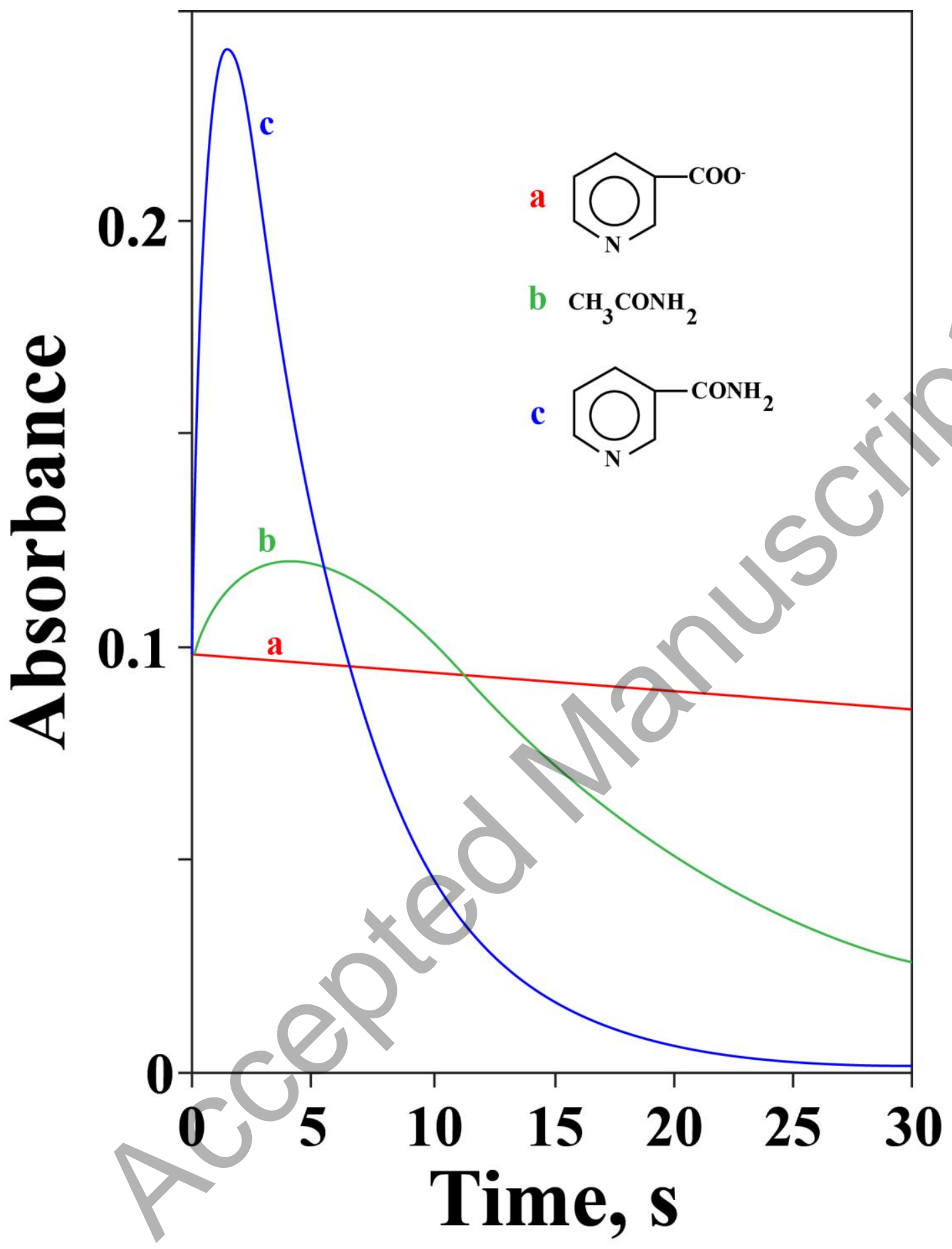

